\title{
Introduction to European family law volume III: Family law in a European perspective
}

\section{Jens M. Scherpe}

In this third volume of the 'European Family Law' book set several core topics of family law are examined from a European and comparative perspective. The specific topics were chosen as between them they cover the topics most debated in family law in the last and presumably also this century. They cover areas where the national family laws have reacted or will need to react to the challenges of societal changes, medical advances and institutional pressures including decisions of the European Courts (on which see relevant contributions in Volume I).

Five of the contributions in this volume cover the relationships between adults. The nature and concept of marriage has changed considerably over the years, particularly since the middle of the last century and towards its end; marriage has - at least nominally - become a partnership of equals. This, for example has become apparent in the financial consequences of divorce and indeed also in the changes the law of divorce itself has seen in the last 70 years. By now all European jurisdictions allow for divorce, and in no jurisdictions can divorce only be based on fault grounds. At the same time in many jurisdictions there exists an increasing legal recognition of unmarried cohabitation, often necessitated by the dramatic increase in couples living in such relationships and of children born outside of marriage. In many jurisdictions (although admittedly predominantly in Western Europe) same-sex relationships have gained legal recognition, often initially as registered partnerships; though increasingly marriage has been opened up to samesex couples as well. The landscape of adult relationships has undergone a profound transformation in many jurisdictions, not only because of the changes that the law of marriage has undergone but also because family laws are moving away from being purely marriage-centric. 
A similar paradigm-shift can also be seen in child law, with which the following four contributions are concerned, which has changed radically from being parent-centred towards being child-centred. The relationship between parents and their children has thus seen a shift towards the child's welfare, which provides the central yardstick for all decisions and the framing of legal rules concerning children. Concepts of parental responsibility are gradually replacing those of parental power, parental custody and parental authority. Adoption is no longer seen as a 'service' for childless couples but as a means to secure the best possible upbringing of particular children, by which permanent legal separation from birth parents is only a last resort. Parentage itself is not the concept that it once was, as artificial reproductive techniques including surrogacy allow the detaching of genetic from gestational and social parenthood. Not even the old adage mater semper certa est is valid in all circumstances anymore. All of these developments, combined with the increased recognition of adult relationships and indeed parenthood in family relationships outside the institution of marriage, have posed and continue to pose significant challenges for 'traditional' family law and particularly for child law. This has led to reforms in many jurisdictions and continues to exert pressure on legislatures to adapt their laws to the realities of modern family life and new technologies.

In many ways this third volume therefore is complementary to the first two volumes of this book set, as its contributions cut across the topics and reports presented in the first and second volumes. ${ }^{1}$ Yet the contributions also stand by themselves and do not require the previous two volumes be read or be to hand. Each of the contributions identifies common themes, developments and trends and sometimes also a convergence of family laws. Therefore the contributions in this volume show that there are indeed both 'institutional' 2 and 'organic' ${ }^{3}$ elements and principles of European Family Law.

1 It is necessary to note that the authors of this volume for organisational reasons unfortunately did not have access to the contributions of the second volume, although ideally that would have been the case. The contributions of the second and the third volume therefore are only brought together in the fourth and final volume on The Present and Future of European Family Law.

2 I.e. deriving directly or indirectly from the institutions discussed in volume one of the book set.

3 I.e. having 'grown' domestically, although often with external influences by institutions or developments in other jurisdictions. 